\title{
Awareness of Cardiovascular Diseases and Knowledge of Cardiovascular Risk Factors and Risk Reduction Measures among Urban and Rural Primary School Teachers in South-Eastern Nigeria
}

\author{
Ofoegbu $\mathrm{CC}^{1 *}$, Ifeadike $\mathrm{CC}^{1}$, Okedo-Alex $\mathrm{IN}^{2}$, Ilika $\mathrm{AL}^{1}$, Onyemachi PEN ${ }^{3}$ and Ekeleme $\mathrm{NC}^{3}$ \\ ${ }^{1}$ Department of Community Medicine, Nnamdi Azikiwe University Teaching Hospital, Nnewi, Anambra State, Nigeria \\ ${ }^{2}$ Department of Community Medicine, Federal Teaching Hospital, Abakaliki, Ebonyi State, Nigeria \\ ${ }^{3}$ Departments of Community Medicine, Abia State University, Abia State, Nigeria
}

*Corresponding author: Ofoegbu CC, Departments of Community Medicine, Abia State University, Abia State, Nigeria, Tel: +2438037417782; E-mail: cosmasofoegbu@yahoo.co.uk

Received date: November 21, 2018; Accepted date: November 27, 2018; Published date: December 03, 2018

Copyright: (c) 2018 Ofoegbu CC, et al. This is an open-access article distributed under the terms of the Creative Commons Attribution License, which permits unrestricted use, distribution, and reproduction in any medium, provided the original author and source are credited.

\section{Abstract}

Aims: To assess the knowledge of cardiovascular risk factors and reduction measures among primary school teachers in rural and urban areas in Anambra state.

Study design: Comparative Cross-sectional study.

Place and duration of study: Urban and rural primary schools in Onitsha North and Dunukofia local government areas of Anambra state between March-October 2015.

Methodology: A random sample of 320 urban and rural primary school teachers (160 in each arm) who were less than 60 years, not pregnant and not on anti-hypertensive drugs were included in the study. Data was collected using a semi-structured interviewer-administered questionnaire and focus group discussions.

Results: Were predominantly female $(97.81 \%)$, mean age of $50.78+5.13$ years. Awareness of cardiovascular disease was higher in urban than rural respondents ( $88 \%$ vs. $76 \%$; $P=0.005)$. Commonest source of information was TV/Radio, more in urban respondents $(72 \%$ vs. $69 \%$; $P=0.008)$. Overall, $63.49 \%$ of respondents had high knowledge while $36.56 \%$ had low knowledge of cardiovascular disease risk factors. Most identified risk factors were lack of exercise, smoking, non-consumption of fruit/vegetables (98.75\%, 96.56\%, 94.38\% respectively) and least identified risk factors were body site of fat deposition, physical inactivity, consumption of packaged processed food (16.25\%, $11.25 \%, 17.19 \%)$. More urban respondents knew non-consumption of fruits/vegetables, fatty foods and stress as risk factors $(P<0.000, P=0.033, P=0.006$ respectively). For risk reduction measures, $61.25 \%$ had high knowledge while $38.75 \%$ had low knowledge. Regular medical check-up, cholesterol check and reduced alcohol intake (49.06\%, $45.94 \%$, and $45.63 \%$ respectively) were the most identified while 5-servings of fruit/day, regular blood sugar $(16.56 \%, 25 \%$ respectively) were the least identified measures. Knowledge of exercising 30-minutes/day, consumption 5-servings of fruit/day, avoidance of fried foods were statistically higher in rural teachers.

Conclusion: There was high awareness of risk factors and reduction measures in rural than urban teachers with no statistical difference overall.

Keywords: Awareness; Knowledge cardiovascular disease; Risk factors; Risk reduction; Teachers

\section{Introduction}

Cardiovascular diseases (CVDs) affect the cardiovascular system and comprise cardiac diseases, vascular diseases of the brain and kidneys, and peripheral arterial diseases [1]. A number of risk factors have been noted as leading to increased chances of cardiovascular diseases. These include cigarette smoking, hypertension, physical inactivity; overweight and obesity, family history of heart disease, ethnicity, sex and age, high blood cholesterol [1-3]. Women generally have the same cardiovascular diseases risk factors as men. However, some risk factors may affect women differently than men. For example, diabetes raises the risk of cardiovascular diseases more in women.
Also, some risk factors, such as birth control pills and menopause, only affect women [4]. Most risk factors increase with age and these increase levels up at age 45-50 years in males and 60-65 years in females [4-6]. With blood cholesterol level greater than $200 \mathrm{mg} / \mathrm{dl}$, cholesterol settles in the inner walls of vessels leading to atherosclerosis $[7,8]$. Nigeria when compared to most other countries has a higher prevalence of risk factors to cardiovascular disease [9]. Cardiovascular disease risk factors cannot be ignored without worsening the health indices of Nigeria, rather these risks should be well researched and its preventive strategies well understood. The risk reduction practices include the avoidance of smoking, exercise, healthy eating, avoidance or moderation of alcohol, regular medical check-up and risk assessment scoring. These risk reduction mechanisms should be taught in schools and early enough before the lifestyle posing risk to 
Citation: Ofoegbu CC, Okedo-Alex IN, llika AL, Ifeadike CC (2018) Awareness of Cardiovascular Diseases and Knowledge of Cardiovascular Risk Factors and Risk Reduction Measures among Urban and Rural Primary School Teachers in South-Eastern Nigeria. J Health Educ Res Dev 6: 289. doi:10.4172/2380-5439.1000289

Page 2 of 8

cardiovascular diseases are developed [4]. Presently in Nigeria as in other developing countries, cardiovascular diseases are on the increase and constitute bulk of admissions in the hospitals. More worrisome is that $20 \%$ of Nigerians suffering from these diseases are unaware that they suffer from it [10]. In its bid to reflect the magnitude of the problems posed by cardiovascular diseases like hypertension and lack of its reduction practices, the World Health Organization (WHO) after the World Hypertension Day of 2012, adopted the 2013 theme of World Health Day as "Healthy Blood Pressure" with the slogan "Healthy Hearts Beat, Healthy Blood Pressure" [10]. Teachers are wide spread in every community and are seen as role models and most of the time they are the resource persons in most events especially in rural settings. Therefore, their awareness and practice will affect the entire community. Apart from the health workers, teachers are the next occupational group that must be involved if we are to rid the society of this deadly scourge. This occupational group interacts with the pupils who are yet to develop the negative lifestyle risk factors associated with developing cardiovascular disease and thus, can make primordial prevention efforts successful [11]. This they will only be able to do if they are knowledgeable about cardiovascular risk factors and risk reduction measures and in turn practice them.

\section{Methodology}

\section{Study area}

The state population is approximately 4.2 million 11 and mainly inhabited by Igbo speaking people who are mostly Christians and most members of the population are farmers, artisans and civil servants. There are 21 local government areas in Anambra state out of which five are urban; five are semi-urban while eleven are rural. The total number of teachers in Anambra state is 10,319 in the 1043 registered primary schools in all the local government areas. Teachers in the five urban local government areas are 3,453 with an average number of 691 per urban LGA. The number of teachers in rural local government areas is 4,133 with an average number of 375 per rural LGA. There are a total of 227 schools in the urban local government, giving an average number of teachers per school as 16 (total number of teachers/ number of schools i.e., 3453/227). In the rural local governments, there are a total of 511 schools, giving an average of 8 teachers per school (total number of teachers/ number of schools, i.e., 4133/511).

\section{Study design}

This is a descriptive, comparative cross-sectional study conducted in Onitsha North LGA (urban LGA) and Dunukofia LGA (rural LGA) both in Anambra state, Southeast of Nigeria.

\section{Sampling technique}

A total of 320 primary school teachers (160 in each LGA) were studied. Teachers above 60 years of age, pregnant women, known hypertensive patients, heart disease patients and diabetics were excluded from the study. Multistage sampling technique was used to select the respondents. Stage 1: one urban and one rural LGA were selected through simple random sampling, Stage 2:10 urban schools and 20 rural schools were selected using simple random sampling and at the third stage, teachers were selected using stratified random sampling.

\section{Data collection and analysis}

Data was collected using a pre-tested semi-structured interviewer administered questionnaire with the aid of a trained research assistant. Focus group discussions were also conducted. Knowledge on cardiovascular risk factors and risk reduction measures had a total scoring of 12 and 14 respectively with a score of +1 for a positive response, -1 for a negative response and 0 for do not know responses. Positive response on exercising for 30 minutes/day and 5-fruit servings/day were scored 2 points each. High and low knowledge was taken as knowledge greater than $50 \%$ and less than/equal to $50 \%$ of the total scores respectively. Data collected was entered and analyzed using IBM-Statistical Packages for Social Sciences Version 22 (IBM-SPSS Version 22) and analyzed after data cleaning and editing. Frequencies and percentages were presented as tables. Statistically significant differences $(\mathrm{P}<0.05)$ were identified using a chi-square and Fisher's exact tests. Manual thematic analysis was carried out on the verbatim FGD transcripts. Some responses were quoted verbatim to capture the original ideas of the participants.

\section{Results and Discussion}

A total of 320 teachers, 160 from each of the study areas were interviewed. The socio-demographic characteristics of these respondents are presented in Table 1 . One hundred and fifty seven respondents (98\%) in both study arms were females and most were married with $>90 \%$ having post-secondary qualifications. There were more never married participants in the urban are than in the rural area $(12.5$ vs. $8.8 \% ; \mathrm{P}=0.02$ ). The mean age was $50.78+5.13$ (Age Range 38-59) with older respondents in the rural area $(\mathrm{P}=0.002)$.

\begin{tabular}{|c|c|c|c|c|c|}
\hline Variables & Urban $(\mathrm{N}=160) \mathrm{n}(\%)$ & Rural $(\mathrm{N}=160)$ n (\%) & Total $(\mathrm{N}=320) \mathrm{n}(\%)$ & Test statistics $\mathrm{X}^{2}$ & P-value \\
\hline \multicolumn{6}{|l|}{ Sex } \\
\hline Male & $3(1.88)$ & $4(2.5)$ & $7(2.19)$ & 0.146 & 0.276 \\
\hline Female & $157(98.13)$ & $156(97.5)$ & $313(97.81)$ & & \\
\hline \multicolumn{6}{|l|}{ Missing } \\
\hline Marital status & & & & Fishers exact & \\
\hline Never married & $8(5)$ & $20(12.5)$ & $28(8.75)$ & 7.819 & $0.026^{* *}$ \\
\hline
\end{tabular}


Citation: Ofoegbu CC, Okedo-Alex IN, llika AL, Ifeadike CC (2018) Awareness of Cardiovascular Diseases and Knowledge of Cardiovascular Risk Factors and Risk Reduction Measures among Urban and Rural Primary School Teachers in South-Eastern Nigeria. J Health Educ Res Dev 6: 289. doi:10.4172/2380-5439.1000289

Page 3 of 8

\begin{tabular}{|c|c|c|c|c|c|}
\hline Married & $152(95)$ & $138(86.25)$ & $290(90.63)$ & & \\
\hline Divorced & 0 & $2(1.25)$ & $2(0.63)$ & & \\
\hline Educational & & & & Fishers exact & \\
\hline FSLC & $5(3.13)$ & $4(2.5)$ & $9(2.81)$ & 22.767 & $0.02^{\star *}$ \\
\hline TCII & 0 & $4(2.5)$ & $4(1.25)$ & & \\
\hline OND & 0 & $2(1.25)$ & $2(0.63)$ & & \\
\hline HND & $1(0.625)$ & 0 & $1(0.28)$ & & \\
\hline NCE & $18(11)$ & $4(2.5)$ & $22(6.88)$ & & \\
\hline BED & $22(13.75)$ & $32(20)$ & $54(16.88)$ & & \\
\hline Postgraduate & $115(71.88)$ & $114(71.5)$ & $229(71.56)$ & & \\
\hline \multicolumn{6}{|l|}{ Age } \\
\hline Below 50 years & $85(53.13)$ & $75(46.88)$ & $160(50)$ & 7.882 & $0.002^{*}$ \\
\hline Above 50 years & $60(37.50)$ & $100(62.50)$ & $160(50)$ & & \\
\hline \multicolumn{6}{|c|}{ Mean 50.78+5.13 Age Range 38-59 } \\
\hline Religion & & & & Fishers Exact & \\
\hline Roman catholic & $98(61.25)$ & $92(57.5)$ & $190(59.38)$ & 2.985 & 0.55 \\
\hline Anglican & $45(28.13)$ & $52(32.5)$ & $97(30.31)$ & & \\
\hline Pentecostal & $17(10.63)$ & $14(8.75)$ & $31(9.69)$ & & \\
\hline Traditional religion Islam & 0 & $1(1.25)$ & $2(0.63)$ & & \\
\hline \multicolumn{6}{|c|}{${ }^{* *}=$ Fishers Exact statistically significant } \\
\hline${ }^{*}=$ Chi-square statistically & & & & & \\
\hline
\end{tabular}

Table 1: Socio demographic characteristics of respondents.

Awareness of cardiovascular diseases, source of information on CVDs and knowledge of cardiovascular disease risk factors is shown in Table 2. Awareness of cardiovascular disease was higher in urban than rural respondents $(88 \%$ vs. $76 \% ; \mathrm{P}=0.005)$. Commonest source of information was TV/Radio, more in urban respondents ( $72 \%$ vs. $69 \%$; $\mathrm{P}=0.008$ ).

More rural than urban respondents identified increased alcohol intake $(43.75 \%$ vs. $25 \%$; $\mathrm{P}<0.001)$ and fat deposition on the waist
(22.5\% vs. $10 \% ; \mathrm{P}=0.007)$ as risk factors More rural than urban respondents wrongly identified consumption of vegetables as a risk factor $(10 \%$ vs. $1.25 \%$; $\mathrm{P}<0.001)$ more urban teachers identified consumption of fatty foods as a risk factor ( $70 \%$ vs. $67.5 \%$; $\mathrm{P}=0.033)$. There was no statistically significant difference in the awareness of overweight, physical inactivity, smoking, and consumption of processed packaged foods and lack of exercise between the urban and the rural respondents.

\begin{tabular}{|c|c|c|c|c|c|}
\hline Variables & Urban $(\mathrm{N}=160)$ n (\%) & Rural $(\mathrm{N}=160)$ n (\%) & Total $(\mathrm{N}=320) \mathrm{n}(\%)$ & Test statistics $\mathrm{X}^{2}$ & P-value \\
\hline \multicolumn{6}{|c|}{ Have you heard of CVD } \\
\hline Yes & $141(88.13)$ & $124(77.5)$ & $265(82.81)$ & 6.345 & $0.005^{*}$ \\
\hline No & $19(11.88)$ & $36(22.5)$ & $55(17.19)$ & & \\
\hline \multicolumn{6}{|c|}{ If yes what source } \\
\hline Radio/TV & $102(72.34)$ & $86(69.36)$ & $188(58.75)$ & 29.392 & $0.008^{\star *}$ \\
\hline Friend & $16(11.35)$ & $16(12.90)$ & $32(10)$ & & \\
\hline
\end{tabular}


Citation: Ofoegbu CC, Okedo-Alex IN, llika AL, Ifeadike CC (2018) Awareness of Cardiovascular Diseases and Knowledge of Cardiovascular Risk Factors and Risk Reduction Measures among Urban and Rural Primary School Teachers in South-Eastern Nigeria. J Health Educ Res Dev 6: 289. doi:10.4172/2380-5439.1000289

\begin{tabular}{|c|c|c|c|c|c|}
\hline Neighbor & 10(7.09) & 0 & 10(3.13) & & \\
\hline Newspaper & $8(3.55)$ & 0 & $8(2.5)$ & & \\
\hline Heath company & $5(3.55)$ & $20(16.13)$ & $25(7.8)$ & & \\
\hline \multirow[t]{2}{*}{ School } & 0 & $2(1.61)$ & $2(0.63)$ & & \\
\hline & 141 & 124 & & & \\
\hline \multicolumn{6}{|c|}{ Which of these is a risk of heart disease } \\
\hline \multicolumn{6}{|l|}{ Consumption of fatty foods } \\
\hline Yes & $120(75)$ & $108(67.5)$ & $228(71.25)$ & 2.197 & $0.033^{*}$ \\
\hline No & $40(25)$ & $52(325)$ & $92(28.75)$ & & \\
\hline \multicolumn{6}{|c|}{ Consumption of processed packaged foods } \\
\hline Yes & $27(16.88)$ & $28(17.5)$ & $55(17.19)$ & 0.022 & 0.116 \\
\hline No & 133(83.13) & $132(82.5)$ & $265(82.81)$ & & \\
\hline Consumption of fruits vegetables & & & & fishers exact & \\
\hline Yes & $2(1.25)$ & $16(10)$ & $18(5.62)$ & 11.538 & $0.000^{* *}$ \\
\hline No & $158(98.75)$ & $144(90)$ & $302(94.38)$ & & \\
\hline Increased alcohol intake & & & & Fishers Exact & \\
\hline Yes & $40(25)$ & $70(43.75)$ & $1101(34.38)$ & 12.468 & $0.000^{*}$ \\
\hline No & \multirow{2}{*}{$120(75)$} & \multirow{2}{*}{90.56 .25} & \multirow{2}{*}{$210(65.63)$} & & \\
\hline Smoking & & & & & \\
\hline Yes & 158(98.75) & $151(94.38)$ & $309(96.56)$ & 9.889 & 0.126 \\
\hline No & $2(1.25)$ & $9(5.63)$ & 11.(3.44) & & \\
\hline Exercise & & & & Fishers Exact & \\
\hline Yes & $4(2.5)$ & $4(2.5)$ & $4(1.25)$ & 4.038 & 0.061 \\
\hline No & $156(97.5)$ & 156(97.5) & $31.6(98.75)$ & & \\
\hline \multicolumn{6}{|l|}{ Lack of exercise } \\
\hline Yes & $69(43.13)$ & $60(37.5)$ & 129.(40.3) & 1.052 & 0.054 \\
\hline No & $91(56.88)$ & 100 & $191(59.69)$ & & \\
\hline \multicolumn{6}{|l|}{ Physical inactivity } \\
\hline Yes & 14(8.75) & $22(13.75)$ & $36(11.25)$ & & \\
\hline No & 146(91.25) & 138(8.25) & $284(88.75)$ & 2.003 & 0.052 \\
\hline \multicolumn{6}{|l|}{ Overweight } \\
\hline Yes & 101.(63.13) & $106(66.25)$ & 207 (64.69) & 0.342 & 0.79 \\
\hline No & $59(36.88)$ & $54(33.75)$ & $113(35.31)$ & & \\
\hline \multicolumn{6}{|l|}{ Stress } \\
\hline Yes & $68(42.5)$ & 48.(30) & $116(36.25)$ & 5.409 & $0.006^{*}$ \\
\hline No & $92(57.5)$ & $112(70)$ & $204(63.75)$ & & \\
\hline
\end{tabular}


Citation: Ofoegbu CC, Okedo-Alex IN, llika AL, Ifeadike CC (2018) Awareness of Cardiovascular Diseases and Knowledge of Cardiovascular Risk Factors and Risk Reduction Measures among Urban and Rural Primary School Teachers in South-Eastern Nigeria. J Health Educ Res Dev 6: 289. doi:10.4172/2380-5439.1000289

Page 5 of 8

\begin{tabular}{|c|c|c|c|c|c|}
\hline \multicolumn{6}{|c|}{ Where is fat deposition most dangerous } \\
\hline Arm & 0 & $4(2.5)$ & $4(1.25)$ & & \\
\hline Head & $7(4.38)$ & $4(2.5)$ & 11(3.44) & 20.615 & $0.007^{* *}$ \\
\hline Waist & $16(10)$ & $36(22.5)$ & $52(16.25)$ & & \\
\hline Chest & $82(51.25)$ & $84(52.5)$ & 166(51.88) & & \\
\hline Legs & $22(51.25)$ & 18(11.25) & $40(12.5)$ & & \\
\hline I don't know & $33(20.63)$ & $14(18.75)$ & $47(14.69)$ & & \\
\hline
\end{tabular}

Table 2: Knowledge of Cardiovascular disease risk factors.

Knowledge of cardiovascular disease risk reduction measures is shown in Table 3. More urban respondents knew the protective effects of regular blood cholesterol check than their rural counterparts (49.38\% vs. $42.5 \%$; $\mathrm{P}=0.042$ ) More rural than urban respondents knew that exercising at least 30 minutes a day $(47.7 \%$ vs. $27.5 \%$; $<<0.001)$, avoidance of fried foods $(38.75 \%$ vs. $30 \% ; \mathrm{P}=0.024)$ and consumption of fruits up to 5 servings per day were protective $(76.25 \%$ vs. $6.88 \%$; $\mathrm{P}<0.001)$. There was no difference in knowledge of smoking avoidance, weight reduction, regular medical, BP and sugar check, reduction of alcohol intake as risk reduction measures.

\begin{tabular}{|c|c|c|c|c|c|}
\hline Variables & Urban $(\mathrm{N}=160) \mathrm{n}(\%)$ & Rural $(\mathrm{N}=160)$ n (\%) & Total $(\mathrm{N}=320) \mathrm{n}(\%)$ & Test statistics & P-value \\
\hline \multicolumn{6}{|c|}{ Which of these can reduce risk of heart disease Exercise } \\
\hline Yes & $51(31.88)$ & $60(37.5)$ & $111(34.69)$ & 1.117 & 0.054 \\
\hline No & 109(68.13) & $100(62.5)$ & $209(65.31)$ & & \\
\hline \multicolumn{6}{|c|}{ Exercising at least 30 minutes a day } \\
\hline Yes & $44(27.5)$ & $62(47.7)$ & 106(33.13) & 12.61 & $0.000^{*}$ \\
\hline No & 116(92.5) & $68(52.37)$ & $184(57.5)$ & & \\
\hline \multicolumn{6}{|c|}{ Smoking avoidance } \\
\hline Yes & $62(38.75)$ & $58(36.25)$ & $120(37.5)$ & 0.213 & 0.083 \\
\hline No & $98(61.25)$ & $102(63.75)$ & $200(62.5)$ & & \\
\hline \multicolumn{6}{|c|}{ Reduction of alcohol intake } \\
\hline Yes & $76(47.5)$ & $70(43.75)$ & $146(45.63)$ & 0.453 & 0.71 \\
\hline No & $84(52.5)$ & $90(56.25)$ & 174(54.38) & & \\
\hline \multicolumn{6}{|c|}{ Consumption of fruits/vegetables } \\
\hline Yes & $47(29.38)$ & $38(23.75)$ & $85(26.56)$ & 1.298 & 0.53 \\
\hline No & $113(10.63$ & $122(26.25)$ & $235(73.44)$ & & \\
\hline \multicolumn{6}{|c|}{ Consumption of up to 5 servings of fruits a day } \\
\hline Yes & $11(6.88)$ & $42(76.25)$ & $53(16.56)$ & 21.731 & $0.000^{*}$ \\
\hline No & 149(93.13) & $118(73.75)$ & $267(83.44)$ & & \\
\hline \multicolumn{6}{|c|}{ Avoidance of fried foods } \\
\hline Yes & $48(30)$ & $62(38.75)$ & $110(34.38)$ & 2.715 & $0.024^{*}$ \\
\hline No & $112(70)$ & $98(61.25)$ & $210(65.63)$ & & \\
\hline
\end{tabular}


Citation: Ofoegbu CC, Okedo-Alex IN, llika AL, Ifeadike CC (2018) Awareness of Cardiovascular Diseases and Knowledge of Cardiovascular Risk Factors and Risk Reduction Measures among Urban and Rural Primary School Teachers in South-Eastern Nigeria. J Health Educ Res Dev 6: 289. doi:10.4172/2380-5439.1000289

Page 6 of 8

\begin{tabular}{|c|c|c|c|c|c|}
\hline \multicolumn{6}{|c|}{ Weight reduction } \\
\hline Yes & $61(38.13)$ & $58(36.25)$ & $119(37.19)$ & 0.123 & 0.087 \\
\hline No & $99(61.88)$ & $102(63.75)$ & $201(62.81)$ & & \\
\hline \multicolumn{6}{|c|}{ Regular blood pressure checks } \\
\hline Yes & $62(38.75)$ & 62 & $124(38.75)$ & 0 & 0.546 \\
\hline No & $98(61.25)$ & $99(61.2)$ & $196(61.25)$ & & \\
\hline \multicolumn{6}{|c|}{ Regular blood sugar test } \\
\hline Yes & 3823.75 & 4226.25 & $80(25)$ & 0.267 & 0.9 \\
\hline No & $122(76.25)$ & $118(73.75)$ & $240(75)$ & & \\
\hline \multicolumn{6}{|c|}{ Regular blood cholesterol } \\
\hline Yes & $79(49.38)$ & $68(42.5)$ & $147(45.94)$ & 1.523 & $0.042^{\star}$ \\
\hline No & $81(50.63)$ & $92(57.5)$ & $173(54.06)$ & & \\
\hline \multicolumn{6}{|c|}{ Regular medical check up } \\
\hline Yes & $77(48.13)$ & $80(50)$ & $157(49.06)$ & 0.113 & 0.084 \\
\hline No & $83(51.88)$ & $80(50)$ & $163(50.94)$ & & \\
\hline
\end{tabular}

Table 3: Knowledge of cardiovascular disease risk reduction measures.

Table 4 shows the overall knowledge of cardiovascular diseases factors in urban and rural primary school teachers in Anambra State. Overall knowledge was higher with the rural teachers than the urban teachers but was not statistically significant $(63.44 \%$ vs. $61.88 \%$; $\mathrm{P}=0.321)$.

\begin{tabular}{|c|c|c|c|c|c|}
\hline Variables & $\begin{array}{l}\text { Urban } \\
(\mathrm{N}=160) \quad n \\
(\%)\end{array}$ & $\begin{array}{l}\text { Rural } \quad(N \\
160) n(\%)\end{array}$ & $\begin{array}{l}\text { Total } \\
(\mathrm{N}=320) \\
(\%)\end{array}$ & $\begin{array}{l}\text { Test } \\
\text { statistics } \\
\mathrm{X}^{2}\end{array}$ & $p$-value \\
\hline \multicolumn{6}{|c|}{ Overall Knowledge } \\
\hline High & $99(61.88)$ & $104(65)$ & $\begin{array}{l}203 \\
(63.44)\end{array}$ & 0.643 & 0.321 \\
\hline
\end{tabular}

\begin{tabular}{|l|l|l|l|l|l|}
\hline Low & $61(38.13)$ & $56(35)$ & $117(36.56)$ & & \\
\hline
\end{tabular}

Table 4: Overall knowledge of cardiovascular diseases risk factors among urban and rural primary school teachers in Anambra State.

Table 5 shows the overall knowledge of cardiovascular disease risk factor reduction measures among urban and rural primary school teachers in Anambra State. Overall knowledge was higher with the rural teachers than the urban teachers but was not statistically significant (64.38\% vs. $58.13 \%$; $\mathrm{P}=0.321)$.

\begin{tabular}{|c|c|c|c|c|c|}
\hline Variables & Urban $(N=160)$ n (\%) & Rural (N 160) n (\%) & Total $(\mathrm{N}=320)(\%)$ & Test statistics $\mathrm{x}^{2}$ & $p$-value \\
\hline \multicolumn{6}{|c|}{ Overall Knowledge } \\
\hline High & $93(58.13)$ & $103(64.38)$ & $196(61.25)$ & 0.593 & 0.221 \\
\hline Low & $67(41.88)$ & $57(35.63)$ & $124(38.75)$ & & \\
\hline
\end{tabular}

Table 5: Overall knowledge of cardiovascular diseases risk reduction measures among urban and rural primary school teachers in Anambra State.

Most respondents in both rural and urban locations hadss an idea of the meaning of cardiovascular disease and this they explained in lay terms. One of the respondents said "It is when the heart fails to perform its normal function" (Response from a rural participant). In another words a respondent explained that cardiovascular disease involves frequent tiredness. In her words "it is when the heart does not pump blood well".
On risk factors for cardiovascular disease, most respondents were able to identify the following risk factors salt intake, high cholesterol, stress and smoking and alcoholism. A female teacher in an urban area said "Another thing that causes cardiovascular disease is being under the sun for too long". Other responses on this were as follows:

"For me, it is when one eats a lot of salt".

"The risk factor is too much sleeping". 
Citation: Ofoegbu CC, Okedo-Alex IN, llika AL, Ifeadike CC (2018) Awareness of Cardiovascular Diseases and Knowledge of Cardiovascular Risk Factors and Risk Reduction Measures among Urban and Rural Primary School Teachers in South-Eastern Nigeria. J Health Educ Res Dev 6: 289. doi:10.4172/2380-5439.1000289

Page 7 of 8

"Those that drink too much alcohol suffer it".

\section{"I think it is because of cholesterol".}

From the above, it is evident that some of the respondents have good knowledge on cardiovascular disease and cardiovascular disease risk factors.

\section{Cardiovascular disease risk factor reduction}

On cardiovascular disease risk factor reduction, responses showed that there was awareness of cardiovascular disease risk factor reduction. Respondents highlighted a number of measures that can reduce cardiovascular disease risk. Some of the responses showed that the measures were exercise, avoidance of fatty foods, and avoidance of salt and were expressed in their words as follows:

"Me I believe it's by doing exercise that one can be healthier". it".

"Some people eat a lot of fried foods that has fat, they should avoid

\section{"Abstaining from salt intake".}

"If people will reduce the way they drink alcohol, the risk will reduce".

"For me, it's by not staying near people that smoke".

\section{Discussion}

General awareness of cardiovascular disease, the knowledge of risk factors for developing cardiovascular diseases, and cardiovascular disease risk reduction measures were assessed. This study found that majority of the respondents were generally aware of CVD and this was significantly higher in urban than the rural teachers. This may have been because of access to multiple sources of information available in urban areas. This finding is similar to other studies where majority of respondents were aware of CVD [12-14]. The common source of information on CVD was from the media (radio and TV) and more urban respondents got their information through the media than their rural counterparts. Health institutions/workers as source of information were higher among rural respondents. Urban inhabitants are likely of higher socioeconomic level and can afford electronic gadgets Radio/TV was also the main source of information in a similar study in Kano, Nigeria [13]. Overall knowledge of risk factors (63.44\%) was lower than that of study among university teachers in Saudi Arabia (73\%) and teaching hospital staff in India (82\%) but higher than that among school children in India (25.4\%). This may have been because university teachers are expected to have better knowledge and exposure than primary school teachers. Also, hospital staffs are expected to have better knowledge about disease risk factors than groups outside the hospital environment. The school children's lower knowledge may be due to the fact that teachers are meant to know more $[12,15,16]$. Smoking was among the top three identified risk factors in our study in keeping with other studies [12,17,18]. Similar with our findings, 5-servings of fruit/day, and consumption of fruits and vegetables were the least identified risk reduction measures in a Polish study [19]. Over 70\% of respondents identified consumption of fatty foods as a risk factor with statistically significant more knowledge in urban than rural respondents. Studies have shown that urban households consume more fatty foods than the rural [20] and this may account for the higher knowledge among urban teachers. Another study among military men in Northern Nigeria [13] showed that only $6.4 \%$ identified consumption of fatty foods as a risk factor for developing CVD. The higher knowledge in the current study might be as a result of the higher educational qualification of the teachers compared to military men and the overall increased awareness in South-East Nigeria. Sixty-five percent of respondents knew overweight as a risk factor without any significant urban-rural differences in contrast to $90 \%$ seen in another study in America [21]. This may be because some of the participants in the American study had health conditions related to heart disease. More access to the media and perceived stressfulness of the urban life may have accounted for more statistically significant knowledge of the consumption of fruits and vegetables among urban teachers. Health workers/institutions being a commoner source of information on CVDs for the rural teachers may account for their statistically significant more knowledge on alcohol intake and body site of fat deposition as risk factors for CVDs. Overall knowledge of risk factor reduction measures (61.25\%) was higher than $32 \%$ recorded in a study among adult Polish residents [19]. This maybe because the Polish study was in a general population with varying educational levels among participants. The most identified measures were regular medical check-up, cholesterol check and reduction of alcohol intake while the least identified were 5-fruit servings and regular blood sugar check. This reflects the low awareness of the relationship of diabetes mellitus to cardiovascular disease among the teachers. Exercise, healthy food habits and smoking cessation were the most identified risk in another study [18]. While urban teachers significantly knew more about regular cholesterol check than the rural ones, the rural teachers identified exercising at least 30 minutes/day, 5fruitservings /day and avoidance of fried foods significantly more than the urban teachers. This may be to the likelihood that cholesterol testing may be more readily available in urban than rural areas. The rural teachers may have identified the above measures more because given the nature of rural areas; exercising and fruit consumption may be practiced more there than in urban areas with lesser tendency to consume fried foods.

\section{Conclusion}

There was high awareness of risk factors and reduction measures in rural than urban teachers with no statistical difference overall. It was statistically significant that more urban respondents knew nonconsumption of fruits/vegetables, fatty foods and stress as risk factors while more rural teachers knew excessive alcohol intake and the most important body site off at deposition as risk factors. Knowledge of exercising 30-minutes/day, consumption 5-servings of fruit/day, avoidance of fried foods were statistically higher in rural teachers while only regular cholesterol check was statistically higher in urban teachers. There is imperative to improve health education and awareness creation on CVDs, risk factors and risk reduction measures to teachers in both urban and rural areas of Anambra state.

\section{Acknowledgements}

The authors wish to acknowledge the primary school teachers who participated in the study, the research assistants, residents and consultants of the department of Community medicine, Nnamdi Azikiwe University Teaching Hospital, Nnewi, Anambra state, Nigeria.

\section{Competing Interests}

The authors declare that no competing interests exist. 
Citation: Ofoegbu CC, Okedo-Alex IN, llika AL, Ifeadike CC (2018) Awareness of Cardiovascular Diseases and Knowledge of Cardiovascular Risk Factors and Risk Reduction Measures among Urban and Rural Primary School Teachers in South-Eastern Nigeria. J Health Educ Res Dev 6: 289. doi:10.4172/2380-5439.1000289

Page 8 of 8

\section{Authors' Contributions}

OCC conceived the idea of the research. All authors contributed to the design of the study. All authors participated in data collection. OCC performed the statistical analysis, and wrote the first draft of the manuscript. All authors read and approved the final manuscript.

\section{Ethical Approval}

Ethical approval for the study was obtained from the Ethics Committee of Nnamdi Azikiwe University Teaching Hospital, Nnewi. Informed consent was obtained from all respondents.

\section{References}

1. Nordqvist C (2013) What is Cardiovascular Disease? What Causes Cardiovascular Disease? Medical News Today. MediLexicon Intl. Accessed 4/04/2013.

2. Tim K, Hayley W, Hannah G (2012) Preventing Cardiovascular Diseases. British Nutrition Foundation, p: 4772.

3. British Heart Foundation (2012) Cardiovascular diseases. Accessed 23/03/2012.

4. (2013) What is Coronary Heart Disease?. Accessed 4/04/2013.

5. American Heart Association (2013) Understand Your Risk of Heart Attack. Accessed 03/04/2013.

6. Mackay J, Mensah G, Mendis S (2004) The Atlas of Heart Disease and Stroke. World Health Organization, Geneva.

7. Estruch R, Ros E, Salas-Salvado J, Covas M, Corella D, et al. (2013) Primary prevention of cardiovascular disease with a Mediterranean diet. New England Journal of Medicine 368: 1279-1290.

8. Rhonda B, Okoror T, Iwelunmor J, Taylor K, Degbo A, et al. (2013) An overview of cardiovascular risk factor burden in Sub-Saharan African countries: A socio-cultural perspective. Accessed 06/02/2013.

9. World Health Organization (2012) World health statistics.

10. Kadiri S (2005) Tackling cardiovascular disease in Africa. British Medical Journal 331: 711-712.
11. Gwirtz PA (2008) Teaching the interrelationship between stress, emotions, and cardiovascular risk using a classic paper by Walter Cannon. Advances in Physiology Education 32: 18-22.

12. Aloshin M, Abubaker S, Eldho M, Jisna T, Bharathi D (2016) Assessment of Knowledge and awareness on cardiovascular risk factors in a Teaching Hospital. International Journal of Pharma Research and Health Sciences 4: 1166-1170.

13. Mohamed J (2012) Knowledge of and attitude to cardiovascular disease risk factors among members of Nigerian armed forces. World J Public Health Scientists 1: 23-27.

14. Akintunde AA, Akintunde TS, Opadijo OG (2015) Knowledge of heart disease risk factors among workers in a Nigerian University: A call for concern. Niger Med 56: 91-95.

15. Tomar R, Al Ameer AH, Antony VC (2015) Lifestyle risk factors and cardiovascular disease: exploring the knowledge of cardiovascular disease among university teachers in Saudi Arabia. Indian Journal of Science and Technology.

16. George GM, Sharma KK, Gupta SK (2014) A study of cardiovascular risk factors and its knowledge among school children of Delhi. India Heart Journal 66: 263-271.

17. Abadelmoneim A, Al-Nafisi A (2014) Public knowledge of cardiovasculardiseases and its risk factors in Kuwait: A cross sectional survey. BMC Public Health 14: 1131.

18. Nelofer K, Gomathi KJ, Ahmad S, Shehnaz S, Abdelzaher S (2013) Knowledge of cardiovascular disease risk factor among the non-medical staff of a medical university in UAE. Golf Medical Journal 2: S147-S152.

19. Pikala M, Kaleta D, Wojciech B, Maniecka-Bryla I, Drygas W, et al. (2011) Awareness of cardiovascular prevention methods among residents of post-communist Polish provinces with highest mortality rates. Cent Eur J Public Health 19: 183-189.

20. Obayelu AE, Okoruwa VO, Oni OA (2009) Analysis of rural and urban households' food consumption differential in the North-Central Nigeria: a micro-econometric approach. Journal of Development and Agricultural Economics 1: 018-026.

21. Schweigman K, Eichner J, Welty T, Zhang Y (2006) Cardiovascular disease risk factor awareness in American Indian communities: The Strong Heart study. Ethnicity \& Disease 16: 647-652. 